\title{
Energetic-Particle Synthesis of High-Strength Al(O) Alloys
}

\author{
D. M. Follstaedt, J. A. Knapp, J. C. Barbour, S. M. Myers and M. T. Dugger \\ Sandia National Laboratories \\ Albuquerque, NM 87185-1056
}

\begin{abstract}
High-strength $\mathrm{Al}(\mathrm{O})$ alloys, initially discovered by ion implantation, have now been produced with electroncyclotron resonance plasma deposition and pulsed-laser deposition. The mechanical properties of these deposited alloy layers were examined with nanoindentation, and finite element modeling of the indented layer on Si substrates was used to determine yield stresses for the alloys of $\sim 1-5 \mathrm{GPa}$. The key to these high strengths is the high density of nanometer-size $\gamma-\mathrm{Al}_{2} \mathrm{O}_{3}$ precipitates formed when high concentrations (5-30 at.\%) of oxygen are introduced into aluminum as individual atoms or molecules. The strongest alloys have precipitates as small as $1 \mathrm{~nm}$, implying that such small precipitates block dislocation motion. Based upon previous studies with oxygen-implanted aluminum, improved tribological properties are expected for layers made by the two new deposition methods.
\end{abstract}

\section{Introduction}

Aluminum alloys are important for light-weight components in aerospace applications and are increasingly being used in the transportation industry to reduce energy usage. However there are serious limitations to using aluminum: it has relatively low strength, and its tribological properties are quite poor. Thus larger volumes of aluminum alloy are required for a given load, and the material may not be suitable for applications with sliding contact. To take advantage of the weight reductions with aluminum more fully, alloys with increased strength and reduced adhesion to contacting materials are needed.

We have developed high-strength layers of aluminum with improved tribological properties by ion implanting oxygen into aluminum [1]. This technique can introduce high oxygen concentrations into aluminum (tens of atomic percent) and produce a dense dispersion of very fine (1-3 nm) $\mathrm{Al}_{2} \mathrm{O}_{3}$ precipitates. The thickness of the precipitate layer is limited by the penetration depth of the $\mathrm{O}^{+}$, which is $<\sim 1 \mu \mathrm{m}$ for practical implantation energies. These $\mathrm{Al}(\mathrm{O})$ layers show substantial improvements over conventional aluminum alloys in the two areas of deficiency noted above: precipitation hardening results in yield stresses of 1-3 GPa, exceeding those of conventional Al alloys and like those of hardened steels, and "stick-slip" adhesion to a steel pin in sliding contact is greatly reduced with a resulting low coefficient of friction (0.2) and reduced wear depth [2]. The yield stress was evaluated using ultra-low load indentation ("nanoindentation") coupled with finite-element numerical modeling of the combined response of the layer/substrate to the indenter load. By using the known mechanical properties of the substrate, those of the hard implanted layer can be obtained by fitting the observed response [1]. While these mechanical properties are remarkable for aluminum, the shallow ion range limits the use of these alloyed layers to surface-related applications, and the tribological advantages disappear when the layer is worn away [3]. If the advantages of $\mathrm{Al}(\mathrm{O})$ alloys are to have practical consequences on a commercial scale, methods must be developed to prepare larger quantities of them. Moreover, ion implantation is relatively expensive for treating large areas with high concentrations of implanted species, which limits its applications to small, critical, higher-cost components.

More recently we have developed two plasma synthesis techniques for $\mathrm{Al}(\mathrm{O})$ alloy layers, electron-cyclotron resonance (ECR) plasma deposition [4] and pulsed laser deposition (PLD) [5]. Oxide precipitates similar to those of ion-implanted $\mathrm{Al}(\mathrm{O})$ were produced in these Al-based layers, and yield stresses of a few gigapascals were determined for both types of materials. Both methods are "scalable": increased alloy thicknesses and areas are obtainable by using a larger synthesis apparatus, and commercial treatment of large areas with these methods is 
expected to be economical. Moreover, both methods offer greater control over the composition as a function of depth than does implantation, which could be useful for further improving the properties of $\mathrm{Al}(\mathrm{O})$ layers.

Our current method of analyzing the mechanical properties of $\mathrm{Al}(\mathrm{O})$ alloys makes two important changes from our previous work. First, the layers examined here were deposited on hard Si substrates, whereas the earlier work examined hard implanted layers on soft, well annealed Al substrates. The soft Al substrates deform significantly during indentation, making the measurement less sensitive to the hard overlayer, whereas the measured hardness of such layers on Si more directly reflects the properties of the layer. Deposited layers with increased strength could also have direct implications for the microelectronics industry, since hardened Al conductor lines may show fewer failures in devices due to stress-induced voiding and electromigration [6,7]. Second, we are now using the widely available commercial code ABAQUS to model the deformation response of the layer/substrate combination to indentation, making our methods more readily transferrable to other systems and investigators. Numerical modeling is the key to accurately determining properties that are specific to the alloy layers and independent of the substrate [1]. We use this approach to determine the yield stress and Young's modulus of the $\mathrm{Al}(\mathrm{O})$ alloys.

Below we first describe the synthesis and microstructure of oxygen-implanted aluminum alloys because identification of the oxide phase with transmission electron microscopy (TEM) is most readily demonstrated with them [8]. Then discussions of the two new synthesis methods will be given and TEM images of their microstructures will be interpreted with guidance from the ion-implanted alloys. Ultra-low load indentation results of the deposited layers are then given, and the finite element modeling used to determine their yield stresses and Young's modulus is described. Others have also found that $\mathrm{O}$ implantation strengthens deposited $\mathrm{Al}$ layers on $\mathrm{Si}$ [6], in agreement with our earlier work. Here we also examine vapor-deposited Al layers implanted with $\mathrm{O}$ using our newer methods to compare to our earlier findings, as well as pure Al layers on $\mathrm{Si}$; both materials provide important references for the two new synthesis methods. We find that all three $\mathrm{Al}(\mathrm{O})$ synthesis methods produce layers with high yield stresses: $\sim 1-5 \mathrm{GPa}$. The similar oxides found with these methods are used to conclude that the introduction of $O$ as isolated energetic ions, atoms or molecules is responsible for the high precipitate densities and accompanying high strength.

\section{Synthesis and Microstructure of $\mathrm{Al}(\mathrm{O})$ Layers}

Oxygen-Implanted Alloys. We have previously investigated alloy layers implanted with $\sim 20$ at.\% $\mathrm{O}[8,9]$ ] Here we review TEM diffraction and imaging results from a specimen implanted at room temperature with $1.5 \times 10^{17}$ $\mathrm{O} / \mathrm{cm}^{2}$ at $50 \mathrm{keV}$, followed by $5.7 \times 10^{16} \mathrm{O} / \mathrm{cm}^{2}$ at $25 \mathrm{keV}$. This treatment produced a surface layer with $17 \pm 1$ at. $\% \mathrm{O}$ extending to a depth of $0.11 \mu \mathrm{m}$ [8], which is thin enough to image in plan-view TEM at 120 or $200 \mathrm{kV}$. The specimen was a high-purity aluminum foil that had been annealed $2 \mathrm{hr}$. at $550^{\circ} \mathrm{C}$ prior to implantation to produce large grains ( $\geq 100 \mu \mathrm{m}$ across) that could be tilted to selected orientations and examined as individual crystals.

Four diffraction patterns are shown from this alloy in Figure 1. Figures 1a) and 1b) were obtained after the implanted foil had been subsequently annealed $1 / 2 \mathrm{hr}$. at $550^{\circ} \mathrm{C}$ in vacuum. This anneal was shown to enlarge the precipitates to a wide range of sizes $(2-25 \mathrm{~nm})$ and sharpen their diffracted reflections [8]. The square pattern of intense fcc-Al reflections from a grain in [100] orientation is seen in Fig. 1a), along with weaker reflections (one is arrowed) at $1 / 2$ the radial distance to the $\{220\}$ reflections. If the grain is tilted a few degrees off the [100] zone orientation as in Fig. 1b), some of the fcc-Al reflections become less intense, and their spots can be resolved into two reflections, as seen in the inset. These patterns identify the second phase as $\gamma-\mathrm{Al}_{2} \mathrm{O}_{3}$ (cubic, $\mathrm{a}_{0}=7.90 \AA$ ) [10]. This phase is not the equilibrium oxide of $\mathrm{Al}$, but a metastable structure with a fcc sublattice of $\mathrm{O}^{2-}$ ions and an ordered arrangement of $\mathrm{Al}^{3+}$ interstitial ions [11]. The $\mathrm{O}^{2-}$ sublattice is only $2.5 \%$ smaller than that of fcc $\mathrm{Al}$, and thus a coherent alignment between the two phases occurs when their cubic axes are parallel in all three directions [12]. This alignment is indicated by the doubled reflections like those in the inset of Fig. 1b). The weak reflections (arrowed) in Figs. 1a) and $1 \mathrm{~b}$ ) result from ordering of the $\mathrm{Al}^{3+}$ ions on interstitial sites in the $\mathrm{O}^{2-}$ sublattice.

When the alloy is examined after implantation with no subsequent anneal, smaller precipitates are seen, and the ordering reflections are absent in the diffraction patterns; see Figs. 1c) and 1d). However, tilting off the zone axis again reveals that the bright spots consist of two reflections. The fcc-Al spots become less intense but remain sharp, allowing an additional, very weak and diffuse spot to be detected beside them, as seen in Fig. 1d). The diffuse spot 
Figure 1. TEM images from Al implanted with 17 at.\% O. a) $<100>$ diffraction pattern taken after annealing $2 \mathrm{hr}$. at $550^{\circ} \mathrm{C}$; an ordering reflection from $\gamma-\mathrm{Al}_{2} \mathrm{O}_{3}$ is arrowed. b) Same as a) but tilted off the $\langle 100\rangle$ zone axis. The curved arrow points to an enlarged inset (3x) of a bright spot and shows the spot is actually two aligned reflections from fcc $\mathrm{Al}$ (inner) and $\gamma-\mathrm{Al}_{2} \mathrm{O}_{3}$ (outer). c) $<100>$ diffraction pattern taken after implantation (no anneal). d) Same as c) but tilted $\sim 5^{\circ}$ off the $\langle 100\rangle$ zone axis. The enlarged inset $(3 \mathrm{x})$ shows a diffuse $\mathrm{Al}_{2} \mathrm{O}_{3}$ reflection beside a sharp one of fcc Al. e) Dark-field image obtained with $\mathrm{Al}$ grain off the zone axis, using a diffuse reflection like that inset in d).

is due to very small precipitates (1.5 - 3.5 nm) illuminated in the $\mathrm{Al}$ matrix by dark-field imaging as in Fig. 1e). Finding such diffuse reflections superimposed on every Al reflection just as the oxide reflections are in Fig. 1b) implies that the fcc $\mathrm{O}^{2-}$ sublattice is again present and aligned with the matrix. However, the absence of the additional ordering reflections seen between the intense spots in Figs. 1a) and 1b) indicates that just after implantation the $\mathrm{Al}_{2} \mathrm{O}_{3}$ oxide is disordered, or only weakly ordered. Careful examination of diffraction patterns from a specimen with higher oxygen content (32 at.\%) allows the ordering reflections barely to be detected after implantation (no anneal). We conclude that after implantation at room temperature, very fine $\gamma-\mathrm{Al}_{2} \mathrm{O}_{3}$ precipitates with disordered $\mathrm{Al}^{3+}$ sites have formed in alignment with the matrix. To image the oxides as in Fig. le), the $\mathrm{Al}$ grains are tilted off the zone axis and a faint reflection is used so that the matrix is weakly illuminated, allowing the oxides to be imaged. Tilting the $\mathrm{Al}$ grains out of contrast and dark-field imaging with superimposed oxide reflections are the keys to imaging the precipitates, as discussed for the plasma-deposited $\mathrm{Al}(\mathrm{O})$ alloys below.

To provide references for the plasma-deposited alloys and to compare with our previous work, two specimens with a $650 \mathrm{~nm}$ pure Al film vapor deposited on [100] Si substrates were prepared. The evaporation was done in the ECR chamber described below, using its electron-beam evaporation source with no plasma operating. One was used to provide a reference without $\mathrm{O}$, and the other was subsequently ion implanted at room temperature with 25 $300 \mathrm{keV} \mathrm{O}{ }^{+}$to form an $\mathrm{Al}_{0.95} \mathrm{O}_{0.05}$ alloy throughout its depth. These layers and the plasma-deposited alloy layers used for nanoindentation and finite element modeling as described below are listed in Table I. A pure Al layer with thickness reduced to $150 \mathrm{~nm}$ was deposited onto TEM grid covered with an electron-transparent Si-O film in order to examine its microstructure. The bright-field image in Fig 2) shows some fcc Al grains in contrast with sizes varying from $50 \mathrm{~nm}$ up to $1 \mu \mathrm{m}$ across. Diffraction patterns show ring patterns from the randomly oriented grains of fcc $\mathrm{Al}$. 
Table I. Summary of layers deposited on Si with their hardness their fitted yield stress and Young's modulus.

$$
\text { Alloy Layer }
$$

Pure $\mathrm{Al}, 650 \mathrm{~nm}$ thick

Ion-implanted $\mathrm{Al}_{0.95} \mathrm{O}_{0.05}, 650 \mathrm{~nm}$ thick

ECR $\mathrm{Al}_{0.80} \mathrm{O}_{0.20}, 610 \mathrm{~nm}$ thick

PLD Al $0_{0.80} \mathrm{O}_{0.20}, 340 \mathrm{~nm}$ thick

PLD Al ${ }_{0.71} \mathrm{O}_{0.29}, 430 \mathrm{~nm}$ thick

\section{Hardness*}

$0.9 \pm 0.2 \mathrm{GPa}$

$3.0 \pm 0.4 \mathrm{GPa}$

$3.2 \pm 0.5 \mathrm{GPa}$

$11.2 \pm 0.2 \mathrm{GPa}$

$6.4 \pm 0.5 \mathrm{GPa}$
Yield Stress**

$0.20 \pm 0.02 \mathrm{GPa}$

$0.95 \pm 0.15 \mathrm{GPa}$

$1.3 \pm 0.2 \mathrm{GPa}$

$5.1 \pm 0.2 \mathrm{GPa}$

$2.5 \pm 0.2 \mathrm{GPa}$
Young's Modulus

$82 \pm 8 \mathrm{GPa}$

$79 \pm 7 \mathrm{GPa}$

$66 \pm 6 \mathrm{GPa}$

$160 \pm 10 \mathrm{GPa}$

$114 \pm 10 \mathrm{GPa}$

* Hardness was obtained at an indentation depth of $100 \mathrm{~nm}$.

** Relative uncertainty is quoted. Absolute uncertainty is judged to be no more than $20 \%$.

Figure 2. Bright-field TEM image of $150 \mathrm{~nm}$-thick pure $\mathrm{Al}$ layer deposited in the ECR system showing fcc Al grains $50 \mathrm{~nm}$ to $1 \mu \mathrm{m}$ across.

ECR Plasma Alloys. Alloy layers of $\mathrm{Al}(\mathrm{O})$ with compositions ranging from pure $\mathrm{Al}$ to $\mathrm{Al}_{2} \mathrm{O}_{3}$ have been deposited in our system, which consists of an electron-beam evaporation source positioned downstream from a horizontal ECR oxygen plasma source. Low energy $\mathrm{O}_{2}{ }^{+}$ions and evaporated $\mathrm{Al}$ impinge on the specimen from the two orthogonal sources. This system has a base pressure of $\sim 10^{-9}$ torr, and has been described in detail elsewhere $[4,13]$. The ECR-type plasma source has the advantages that it can operate in the low pressure regime used for the metal deposition and it has a higher ionization rate than other processing plasmas. The composition can be controlled by varying the processing parameters, including $\mathrm{Al}$ deposition rate, $\mathrm{O}_{2}$ flow rate, pressure and microwave power. The ions impinge upon an electrically isolated specimen with an incident kinetic energy of $\sim 30 \mathrm{eV}$, which can be increased to a few hundred electron-volts by biasing the specimen. These features allow isolated $\mathrm{O}$ atoms to be introduced into the depositing Al layer at controlled energies in a manner similar to ion implantation.

For the metallic layers use in this study, an Al deposition rate of $1 \mathrm{~nm} / \mathrm{s}$ was used with a microwave power of $80 \mathrm{~W}$ and an $\mathrm{O}_{2}$ flow rate of $1 \mathrm{sccm}$. Oxygen concentrations and depth profiles were measured using Rutherford backscattering spectrometry (RBS). Specimen bias (up to $100 \mathrm{~V}$ ) was found to have little influence on the precipitate microstructure of the Al-rich alloys. The $\mathrm{O}$ atoms are calculated to penetrate from one to a few monolayers into the $\mathrm{Al}$ with this range of energies[14]. The temperature of the specimen during deposition can also be independently varied by radiative heating. We have found that deposition at elevated temperatures $\left(\sim 400^{\circ} \mathrm{C}\right)$ leads to a roughening of the layer [15], whereas lower temperatures $\left(\sim 100^{\circ} \mathrm{C}\right)$ produce a much smoother layer. The specimens considered here were therefore deposited near $100^{\circ} \mathrm{C}$. 
Figure 3. TEM images of ECR alloy with composition $\mathrm{Al}_{0.74} \mathrm{O}_{0.26}$ deposited at $127^{\circ} \mathrm{C}$ without specimen bias. a) Bright-field image showing fcc Al grains $12-80$ nm across. b) Diffraction pattern showing fcc Al rings. c) Darkfield image obtained with objective aperture on a section of the (111) ring circled in b), showing 1-2 nm precipitates of disordered $\gamma-\mathrm{Al}_{2} \mathrm{O}_{3}$ in weakly illuminated $\mathrm{Al}$ grains.

For nanoindentation testing, a $610 \mathrm{~nm}$ thick ECR alloy with composition $\mathrm{Al}_{0.80} \mathrm{O}_{0.20}$ was used (see Table I). A specimen nearly equivalent to this ECR alloy but with composition $\mathrm{Al}_{0.74} \mathrm{O}_{0.26}$ and only $150 \mathrm{~nm}$ thick was deposited on a grid with a thin film of transparent $\mathrm{Si}-\mathrm{O}$ between the grid bars to allow the layer to be imaged with plan-view TEM. The microstructure of the TEM specimen is seen in the micrographs in Fig. 3. Bright-field images like Fig. 2a) show some fcc Al grains in contrast and allow the range of grain sizes to be determined: 12-80 nm across. This is much smaller than the grain size obtained from the pure Al specimen, seen in Fig. 2). All our observations on numerous specimens show much finer fcc $\mathrm{Al}$ grains when oxygen is introduced by any method, including ECR plasma deposition, PLD, and evaporation in $\mathrm{O}_{2}$ gas ambient. Images obtained with an underfocussed TEM objective lens show Fresnel contrast around the grains, implying that grain-boundary grooving is present on the surface.

The diffraction pattern in Fig. $3 \mathrm{~b}$ ) from the ECR alloy shows bright rings matching fcc $\mathrm{Al}$ from the numerous randomly oriented grains in the diffracting area; no additional phase is detected with diffraction. The dark-field image in Fig. 3c) obtained using a section of the (111) Al ring shows some grains brightly illuminated because they are strongly diffracting into this section. A few areas are very dark; the grains at these positions are oriented such that they diffract no intensity into the section of the ring used for imaging. However, many grains appear gray, indicating that they are diffracting weakly into the selected section of the ring. By using extended exposures and careful focussing to image these areas at high magnification, very fine spots (1-2 nm) are illuminated as in Fig. 3c). These conditions, dark-field imaging with a portion of reciprocal space near the fcc $\mathrm{Al}$ position and examining a grain tilted out of strong diffraction contrast, are like those discussed above for imaging $\gamma-\mathrm{Al}_{2} \mathrm{O}_{3}$ precipitates in the ion-implanted alloy, and the fine particle size is like that expected for precipitates of this phase. The absence of additional detected reflections in the diffraction patterns is also consistent with this identification because the weak, diffuse oxide reflections of $\gamma-\mathrm{Al}_{2} \mathrm{O}_{3}$ with disordered $\mathrm{Al}^{3+}$ are not detectable next to the intense fcc $\mathrm{Al}$ reflections. On this basis, we infer that the fine white spots seen in oxygenated ECR alloys are $\gamma-\mathrm{Al}_{2} \mathrm{O}_{3}$ precipitates.

To check this interpretation, similar dark-field images of the pure Al layer in Fig. 2 were obtained. The images show some bright grains and many weakly diffracting grains with uniform gray contrast but no indication of second phase particles, whereas most weakly diffracting grains in images of ECR alloys show copious numbers of particles. A few grains in pure Al show nanometer-size spots that could be $\mathrm{O}$ contamination, perhaps at grain boundaries. Ionbeam analysis of the pure $\mathrm{Al}$ films does not detect $\mathrm{O}$ within them, indicating concentrations less than a few percent. 
Figure 4. TEM images from PLD $\mathrm{Al}_{0.69} \mathrm{O}_{0.31}$ layer. a) Bright-field image showing grain sizes 5-25 $\mathrm{nm}$ across. b) Electron diffraction pattern showing fcc $\mathrm{Al}$ rings. c) Dark-field image obtained with a section of the (111) $\mathrm{Al}$ ring as indicated in $\mathrm{b}$ ), showing $1 \mathrm{~nm} \gamma-\mathrm{Al}_{2} \mathrm{O}_{3}$ precipitates.

PLD Alloys. The PLD alloy layers were deposited in an all-metal vacuum system with a base pressure of $10^{-9}$ Torr. A Q-switched Nd-YAG laser was used to ablate high purity $\mathrm{Al}$ and $\mathrm{Al}_{2} \mathrm{O}_{3}$ targets at $10 \mathrm{hz}$ repetition rates. The laser output was frequency quadrupled to a wavelength of $266 \mathrm{~nm}$ to maximize power absorption near the surface of the targets, as discussed elsewhere [16]. The pulse width was was $20 \mathrm{~ns}$ with power densities of $1-2 \mathrm{~J} / \mathrm{cm}^{2}$. The laser was focussed to a spot $1-2 \mathrm{~mm}$ in diameter with the substrate $\sim 7 \mathrm{~cm}$ away. The $\mathrm{Al}(\mathrm{O})$ layers were formed by ablating the $\mathrm{Al}$ target for $x$ shots, switching to the $\mathrm{Al}_{2} \mathrm{O}_{3}$ target for $y$ shots, and then repeating. The amount of each target deposited in a cycle was kept low enough ( $\sim 1$ atomic layer) to achieve a uniform composition. The $x: y$ ratio determined the atomic fraction of $O$ in the layer. The $O$ content and the layer thickness were measured with RBS. A key feature for obtaining uniform depositions was the use of a particle filter to remove molten droplets of $\mathrm{Al}$ that were occassionally ejected when the Al target got too hot. The filter used a high-speed ( $3000 \mathrm{rpm})$ wheel with a window whose position was synchronized with the laser to allow the plasma plume to pass through it but block the slower moving droplets, as described in detail elsewhere [5]. The layer is thus formed by energetic $\mathrm{Al}$ and $\mathrm{O}$ atoms $(\sim 5-10 \mathrm{ev})$ from the ablated plasma [17]. Layers were deposited at room temperature on [100] Si for indentation and on transparent TEM grids for microstructural analysis.

The microstructures observed with TEM are very similar to those for the ECR deposition, but with smaller Al grains and slightly smaller precipitate sizes. The Al grains were observed to be 5-25 nm across, as seen in Fig. $4 \mathrm{a}$ for a $95 \mathrm{~nm}$ thick layer with 31 at.\% O. Electron diffraction patterns like that in Fig. 4b) show only fcc Al rings. Darkfield imaging in grains tilted out of diffraction contrast illuminated a high density of fine white particles $0.8-1.4 \mathrm{~nm}$ across, as seen in Fig. 4c). The above discussion concerning identification of the precipitates in ECR alloys applies equally well to the PLD alloys, and the nanometer-size particles are again believed to be disordered $\gamma-\mathrm{Al}_{2} \mathrm{O}_{3}$ precipitates in an fcc Al matrix.

\section{Indentation Testing and Finite-Element Modeling}

In general, the apparent hardness of a thin layer to indentation can be strongly influenced by the properties of its substrate, especially when the indented depth is a substantial fraction of the layer's thickness. The substrate's influence is expected to be most noticeable when its mechanical properties are very different from the layer. These 
Figure 5. Load vs. depth curves for nanoindentation of three layers deposited on $\mathrm{Si}$ : pure $\mathrm{Al}$ (no plasma), $\mathrm{Al}$ implanted with 5 at.\% $\mathrm{O}$, and ECR-plasma treated $\mathrm{Al}_{0.80} \mathrm{O}_{0.20}$.
Figure 6. Load vs. depth curves for nanoindentation of PLD layers of $\mathrm{Al}_{0.80} \mathrm{O}_{0.20}$ and $\mathrm{Al}_{0.71} \mathrm{O}_{0.29}$ on $\mathrm{Si}$, and best-fit simulations to determine the indicated yield stresses.

effects were found to be especially notable in our earlier work with $\mathrm{O}$ implanted into thick, well annealed $\mathrm{Al}[1,2]$. This very soft substrate greatly reduced the apparent hardness, even though the implanted $\operatorname{Al}(\mathrm{O})$ layers were intrinsically very hard. For this reason, finite-element modeling was adapted to the problem.

The yield stresses of $\mathrm{Al}$ implanted with 5,10 and 20 at.\% $\mathrm{O}$ were evaluated with nanoindentation and modeling, and found to increase from 1.4 to $2.9 \mathrm{GPa}$ with increasing $\mathrm{O}$ in this range [2]. The size of the fine oxides seen with TEM was used to calculate the density of precipitates and their interparticle spacing, assuming that all $O$ had precipitated as spherical particles of $\gamma-\mathrm{Al}_{2} \mathrm{O}_{3}$. When this microstructural information was used in conventional metallurgical models for precipitation hardening, yield stresses were predicted that agree with the evaluated values. This work indicates that the implanted $O$ is directly responsible for the high strengths of the implanted layers.

Nanoindentation. The mechanical properties of the deposited layers studied here were examined with indentation at Nano Instruments, Inc. [18]. The diamond tip of a NanoIndenter II ${ }^{\circledR}$ instrument was pushed into the material under fine depth control and the response force of the material was measured as a function of depth. This force measures the net hardness of the layer/substrate combination. The force was also measured during withdrawal of the tip, which gives the apparent elastic modulus. If the loading force is held constant on the inserted indenter, the material relaxes and the tip moves in further, giving an indication of the creep properties of the layer. In evaluating the ECR alloys, the surface was first located and the tip was inserted at $5 \mathrm{~nm} / \mathrm{s}$ to a depth of $50 \mathrm{~nm}$. The force was held constant for 15 seconds, and then the tip retracted. The tip was then similarly re-inserted at the same position to $100 \mathrm{~nm}$ and then to $200 \mathrm{~nm}$ at 10 and $20 \mathrm{~nm} / \mathrm{s}$, respectively. Each specimen was indented in this manner at 10 positions in an array $15 \times 60 \mu \mathrm{m}$ in size.

Typical indentation response curves are shown in Fig. 5 for three specimens: the $650 \mathrm{~nm}$-thick pure Al layer, this same layer implanted with 5 at. $\% \mathrm{O}$, and an $\mathrm{Al}_{0.80} \mathrm{O}_{0.20} \mathrm{ECR}$ alloy with a similar thickness of $610 \mathrm{~nm}$. The force needed to indent the pure $\mathrm{Al}$ film is clearly lower than the others, indicating that it is much softer. In addition, the pure $\mathrm{Al}$ film shows a much greater degree of creep as indicated by its greater relaxation (longer horizontal section) at constant load. The hardnesses of these specimens, defined as the load divided by the contact area, were $>3 \mathrm{GPa}$ for the specimens with $\mathrm{O}$, but $<1 \mathrm{GPa}$ for the pure Al specimen. The hardness values show little variation with indentation depth, implying that they are not strongly influenced by the hard Si substrate. A simple estimate of yield stress is to divide hardness by 3 [19], which gives yield stresses of $1.1 \mathrm{GPa}$ (ECR alloy), 1.0 GPa (implanted alloy) and $0.3 \mathrm{GPa}$ (pure Al). The Youngs' modulus of these materials can be obtained from the slope of the unloading 
Table II. Materials parameters held constant in modeling load-displacement curves.

\begin{tabular}{cccccc} 
Material & Young's Modulus (GPa) & Poisson's Ratio & & Yield Stress (GPa) & Work Hardening(GPa) \\
\cline { 2 - 3 } Diamond & 1160.9 & 0.100 & & na & na \\
Si & 162.9 & 0.223 & 5.60 & 0 \\
$\mathrm{Al}(\mathrm{O})$ & - & 0.347 & - & 1.50
\end{tabular}

portions of the response curves as described in Ref. [20,21]. However, the modulus values systematically increase with indentation depth, indicating that the rigid Si substrate influenced the measurements.

Figure 6 shows indentation response curves for two PLD layers: $\mathrm{Al}_{0.80} \mathrm{O}_{0.20}-340 \mathrm{~nm}$ thick, and $\mathrm{Al}_{0.71} \mathrm{O}_{0.29}-430$ $\mathrm{nm}$ thick. The forces needed to penetrate to the same depths are significantly higher $(\sim 6 \mathrm{x})$ for the PLD Al(O) layers than for the pure Al layer in Fig. 5. The hardnesses of the two PLD layers at $100 \mathrm{~nm}$ indentation depth are $11.2 \pm 0.2$ $\mathrm{GPa}$, and $6.4 \pm 0.5 \mathrm{GPa}$, respectively, indicating that these $\mathrm{Al}(\mathrm{O})$ alloys have yield stresses in the gigapascal range. However, since this indented depth is $25-30 \%$ of the layer thickness, the hardness estimate of yield stress may not be reliable. The harder PLD layer shows less creep to greater indentation depths during the $15 \mathrm{sec}$ hold at constant load than does the second PLD layer, and both show much less creep than does the pure Al layer as seen in Fig. 5 .

Finite Element Modeling. In this study, we have used the commercial large-strain, finite-element code ABAQUS [22] to model indentation of $\mathrm{Al}(\mathrm{O})$ layers on $\mathrm{Si}$. The congruent gradient solver in the Explicit version was used; it is tuned for large, non-linear problems and allows modeling the changing contact area and load between the indenter and material. Indentations were modeled with a two-dimensional, cylindrically-symmetrical mesh, as described in detail elsewhere [5]. A theoretical conical indenter shape was used with the same area vs. depth as found by independently calibrating the tip shape by indenting silica glass and single-crystal Al.

The indenter tip, layer and substrate were divided into deformable elements using a computer generated mesh [23], as seen in Fig. 7 for the ECR Al(O) alloy layer on Si. The element size is smallest in the alloy layer (610 $\mathrm{nm}$ thick), and also decreases as the indenter axis is approached. Typically, substrates are modeled with a transition region $500 \mathrm{~nm}$ thick using smaller elements than those below it in the "bulk", which is modeled to a total depth of 6 to $8 \mu \mathrm{m}$. The radial width of the mesh is equal to the depth. Figure 7 shows the mesh after indentation to $200 \mathrm{~nm}$.

Figure 7. Mesh used in the finite-element modeling to simulate indentation of the ECR - plasma-treated $\mathrm{Al}_{0.84} \mathrm{O}_{0.26}$ layer, shown with the pin at $200 \mathrm{~nm}$ depth.
Figure 8. Load vs. depth response curves for nanoindentation of pure $\mathrm{Al}$ and ECR plasma-treated $\mathrm{Al}_{0.84} \mathrm{O}_{0.26}$ (from Fig. 5), and best-fit simulations. 
The plastic deformation zone for this example extends to the through the layer and out to a radius of $1 \mu \mathrm{m}$. Each material in the model was treated using the plasticity model in ABAQUS with a Mises yield surface and associated plastic flow. The density, Young's modulus, Poisson's ratio and stress-strain curve were input, with the yield stress being defined at $0.2 \%$ plastic strain. Table II shows the parameter values used. The diamond tip was modeled as a purely elastic solid. The Si substrate was treated as an elastic-plastic material with no work hardening. The $\mathrm{Al}(\mathrm{O})$ alloy layers were modeled as elastic-plastic solids using Poisson's ratio for pure $\mathrm{Al}$ and the work hardening rate of $\mathrm{Al}$ with impurities [24]. The Young's modulus and yield stress of the layers were then treated as adjustable parameters to fit the observed load vs. depth curves in Fig. 4. An interpolation method was developed to optimize the choice for obtaining a simultaneous fit of these two parameters to both the loading and unloading portions of the curves [23], and the best-fit values are given in Table I..

The relative uncertainties in the yield stress and Young's modulus values that are quoted in Table $I$ are a combination of three sources of error. First, the experimental results show scatter from one indent to another; part of the quoted error is due to the standard deviation of this scatter. Another small source of error is inherent in the linear interpolation procedure for extracting the yield and modulus from several simulations. Third, the simulations generally show slightly more curvature in the load vs. depth response than is observed experimentally. Fitting the data from $0-100 \mathrm{~nm}$ depth gives a slightly different value than fitting from $100-200 \mathrm{~nm}$. Less well known is the uncertainty in the yield stress due to inaccuracies in the assumptions that went into the model, such as using the work hardening rate for $\mathrm{Al}$ with other impurities. We judge that errors in such assumptions have shift the fitted values by no more than $20 \%$ from the actual value.

Figure 8 shows the indentation response data for the ECR Al(O) layer and the pure Al layer (both seen in Fig. 5), along with their theoretical fits using ABAQUS. The yield stresses of the ECR alloy is $1.3 \pm 0.2 \mathrm{GPa}$, which verifies its high strength as expected from the comparison to the implanted layer, the hardness-based estimate, and its microstructure. The fit to the implanted layer (not shown) gave a yield stress of $0.95 \pm 0.15 \mathrm{GPa}$, which is slightly

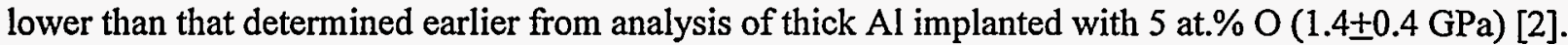

The yield stress of the pure Al layer, $0.20 \pm 0.02 \mathrm{GPa}$, is far below that of the specimens with $\mathrm{O}$, but is much higher than that of well annealed $\mathrm{Al}, 0.041 \mathrm{GPa}$. The hardness of this pure $\mathrm{Al}$ layer, $0.9 \mathrm{GPa}$, is also more than twice that of cold-rolled Al [19]. The high strength of this vapor-deposited Al layer is apparently due to its small grain size, $0.05-1 \mu \mathrm{m}(0.4 \mu \mathrm{m}$ appears typical; see Fig. 2). Others have also observed strengthening of Al layers due to reduced grain sizes [25]. A similar yield stress was found for a second pure Al deposited layer. We have also modeled the measured load versus depth curve for an $\mathrm{Al}$ single crystal indented to a depth of $500 \mathrm{~nm}$, and obtain good agreement with no adjustable parameters by using the published stress-strain curve for pure $\mathrm{Al}$ [24]. This result provides confirmation of our overall approach of using ABAQUS to model nanoindention response curves.

The fitted values for Young's modulus are also listed in Table I for pure Al layers, 5 at.\% O-implanted $\mathrm{Al}$ and the ECR Al layer. These values are equal to or slightly larger than the value for pure Al, 68-72 $\mathrm{GPa}$ [19]. Thus the high yield stress of these layers is attained by sustaining higher strains before the onset of plastic deformation.

Using the approach discussed above, modeled response curves were also fitted to the nanoindentation data for the PLD alloys and pure Al. Good fits were obtained to both the indenting portion of the data and to the slope of the data upon withdrawal of the indenter tip, as seen in Fig. 6. The harder PLD Al(O) layer has an exceptionally high yield stress, $5.1 \pm 0.2 \mathrm{GPa}$, while that of the second layer is also very high at $2.5 \pm 0.2 \mathrm{GPa}$. The Young's modulus values for these very strong layers, $160 \pm 10 \mathrm{GPa}$ and $114 \pm 10 \mathrm{GPa}$, are noticeably higher than that for pure $\mathrm{Al}$, indicating that they are being made stiffer by the high volume fractions ( $\approx$ atomic fraction) of $\gamma-\mathrm{Al}_{2} \mathrm{O}_{3}$ in the $\mathrm{Al}$ matrix.

\section{Discussion}

All three synthesis methods have produced hard $\mathrm{Al}(\mathrm{O})$ alloys with yield stresses in the gigapascal range. The yield stress and Young's modulus values for the alloy layers on Si discussed here are summarized in Table I. For comparison, the yield stress of 7075-T6 aerospace $\mathrm{Al}$ is $0.5 \mathrm{GPa}$; the $\mathrm{Al}(\mathrm{O})$ layers analyzed here are all much stronger than such conventional high-strength engineering alloys, and are a significant discovery in the development 
of improved $\mathrm{Al}$ alloys. The key microstructural feature responsible for the observed strength is the high density of $\gamma-\mathrm{Al}_{2} \mathrm{O}_{3}$ precipitates produced by these methods. The high density results because high $\mathrm{O}$ concentrations $(5-30$ at. $\%)$ can be introduced by these methods and the oxide nucleates readily.

The three methods have common features that are responsible for this microstructure. Atomic or molecular oxygen species are injected athermally and ballistically forced into the $\mathrm{Al}$ matrix at the desired concentration, despite the very low equilibrium solid solubility, $<3 \times 10^{-8}$ at.\% [26]. The low solubility is due to a high chemical reactivity between $\mathrm{O}$ and $\mathrm{Al}$ which drives $\mathrm{Al}_{2} \mathrm{O}_{3}$ formation. This high reactivity promotes nucleation, and the $\gamma$ phase is probably selected because its near lattice match to fcc Al implies a lower interfacial energy between the two phases than achievable with the equilibrium $\alpha$ phase (corundum) [11]. We also believe that the introduction of $O$ as individual ions, atoms, or molecules leads to a high nucleation density because these species are uniformly dispersed when embedded in the Al. All three synthesis methods introduce $\mathrm{O}$ in this manner, although their $\mathrm{O}$ energies vary widely: from $\sim 1 \mathrm{eV}$ (PLD) to $\sim 1 \mathrm{MeV}$ (ion implantation). We therefore suggest that other ion-beam or plasma deposition methods should produce similar microstructures, including plasma-imersion ion implantation, ion-assisted chemical vapor deposition, ion-beam assisted deposition and ion plating.

A key mechanism by which oxygen strengthens the $\mathrm{Al}$ matrix is believed to be dispersion hardening by the precipitates. This is the basic mechanism proposed by Orowan [27] for strengthening with precipitates that require dislocations to bow around them. The expression for the stress needed to make dislocations in a ductile matrix bow around particles separated by distance $\lambda$ and leave loops around them has the form:

$$
\tau \approx \mathrm{Gb} / \lambda
$$

where $G$ is the shear modulus of the material and $b$ is the dislocation Burgers vector. This expression predicts that $a$ high density of particles with a correspondingly small separation will exhibit high strengths when the interparticle spacing approaches Burgers vector dimensions (i.e., as $\lambda \rightarrow b$ ). This situation is achieved in our alloys because of the sizable oxide volume fraction and the high precipitate density. The work with O-implanted $\mathrm{Al}$ using several concentrations and precipitate sizes [2] gives varying yield strengths that agree with more detailed evaluations of this conventional metallurgical theory [28,29]. This agreement is notable because the theory is being applied to much higher precipitate densities $\left(\sim 3 \times 10^{19} \mathrm{ppt} / \mathrm{cm}^{3}\right)$ and much smaller precipitate diameters $(\sim 1 \mathrm{~nm})$ than those for which it was developed. Extending the numerical evaluations [1,2] of dispersion hardening theory for $\mathrm{Al}_{0.80} \mathrm{O}_{0.20}$ to $1 \mathrm{~nm}$ size oxides predicts yield stresses of 4-5 GPa like that of the hardest layer examined here. Another mechanism, strengthening due to strain fields around coherent precipitates, may also contribute substantially to the strength [1].

The high yield stresses obtained with the two plasma methods are expected to result from the same hardening mechanisms, perhaps with additional contributions from the reduced grain sizes. However, the observed values do not all exhibit the expected variations with $O$ content. For instance, the yield stress of the ECR layers with 26 at.\% $O$ is like that of ion-implanted layers with 5 at.\% $\mathrm{O}$ instead of the higher levels $(\sim 3 \mathrm{GPa})$ obtained at such concentrations with implantation [1]. Also, the PLD layer with 20 at.\% O has a yield stress (5.1 GPa) that is twice that of the layer with 29 at.\% O. These unexpected reductions in strength for plasma-deposited alloys with high $\mathrm{O}$ contents indicate that in some layers not all $O$ is equally effective in strengthening the matrix, and imply some differences in the depositions. For instance, if part of the oxide was forming on grain boundaries, it might not strengthen the material to the same degree. Initial observations with the ECR system indicate that deposition temperature is important in determining strength; depositions at $400^{\circ} \mathrm{C}$ produced much softer layers.

It is notable that $\gamma-\mathrm{Al}_{2} \mathrm{O}_{3}$ precipitates as small as $1 \mathrm{~nm}$ across appear to be effective in strengthening the material. For dispersion hardening, this implies that such small particles are effective in blocking dislocation motion. The resistance of a second phase to mechanical shear can be taken as a measure of its ability to block dislocations from passing through it. If the resistance to shear is limited by the intrinsic strength of the particle, the critical parameter is the Peierls stress. For $\mathrm{Al}_{2} \mathrm{O}_{3}$, this is the shear modulus divided by $\sim 13$ [30], which gives a value of $\sim 14 \mathrm{GPa}$ for the $\alpha$ phase of $\mathrm{Al}_{2} \mathrm{O}_{3}$; that for $\gamma-\mathrm{Al}_{2} \mathrm{O}_{3}$ is expected to be similar. Since this value exceeds the yield stresses determined for our $\mathrm{Al}(\mathrm{O})$ alloys, it is consistent with the oxide precipitates blocking dislocation motion.

Bader et al. have also found that $\mathrm{Al}$ is strengthened by fine oxide precipitates [6]; their Fig. 3 shows $\sim 6 \mathrm{~nm}$ features believed to be oxide precipitates. In their studies, $0.5 \mu \mathrm{m}$-thick Al films on Si were ion implanted with 
Figure 9. Friction coefficients plotted as a function of cycles during pin-on-disk testing using a $440 \mathrm{C}$ stainless steel pin loaded to produce a contact Hertzian stress of $32 \mathrm{MPa}$. Two specimens were tested: a pure $\mathrm{Al}$ disk, and a similar disk implanted with 10 at.\% $O$. The friction for the untreated $\mathrm{Al}$ disk increases rapidly during the first cycle and oscillates about an average value of $\sim 1$ due to stick-slip adhesion. Implantation of $\mathrm{O}$ reduces the coefficient of friction to $\sim 0.2$ until the implanted layer wears away, which occurs after $\sim 35$ cycles in the test shown.

3 at.\% $\mathrm{O}$ and thermally cycled between 40 and $400^{\circ} \mathrm{C}$. In specimens with grains large enough (5.6 $\left.\mu \mathrm{m}\right)$ not to dominate the strength of the layer, stresses up to $\sim 0.4 \mathrm{GPa}$ were sustained in tension during the cooling portion of the cycle, indicating that the yield stress exceeds this value. These authors also interpreted the high yield stress as due to dispersion strengthening by oxides formed during the thermal cycling.

The Young's modulus values determined from fitting the simulations are also listed in Table I. The values for the pure Al layers, as well as the implanted and ECR layers, agree or are somewhat higher than the value for singlecrystal $\mathrm{Al}, 68 \mathrm{GPa}$ [19]. The modulus more than doubles on going from pure $\mathrm{Al}$ to the high-strength $\mathrm{Al}_{0.80} \mathrm{O}_{0.20} \mathrm{PLD}$ layer. Since Young's modulus for $\mathrm{Al}_{2} \mathrm{O}_{3}(390 \mathrm{GPa})$ is much higher than that of $\mathrm{Al}$, an increase in this value for alloys is expected because the volume fraction of $\gamma-\mathrm{Al}_{2} \mathrm{O}_{3}(\approx$ atomic fraction of $\mathrm{O})$ is quite substantial. However, the changes in modulus with $O$ additions are far less than the corresponding changes in yield stress, which are up to 25 times. This means that the stress vs. strain curves for the strong alloys not only have initial slopes higher than that of pure Al due to their higher modulus, but the alloys also can be strained to a greater degree before the onset of plastic deformation.

Our earlier work with O-implanted $\mathrm{Al}$ has shown that this treatment greatly improves the tribological properties of $\mathrm{Al}[2,3]$. In pin-on-disk testing, "stick-slip" adhesion of a steel pin to an implanted Al disk was greatly reduced relative to pure $\mathrm{Al}$ and the average coefficient of friction decreased from $\sim 1$ to 0.2 as seen in Fig. 9, while the wear track showed fine, parallel grooves characteristic of an abrsive wear mechanism, instead macroscopic material transfer that is typical of adhesive wear. The improvements persisted longer for stronger layers with higher $O$ contents, but benefits were obtained with as little as 5 at.\%. The benefits disappeared when the $\mathrm{Al}(\mathrm{O})$ layer was worn away after several tens of cycles. The plasma deposition techniques allow thicker layers to be produced, and may give an improved tribological surface with a wear life longer than that with ion implantation. In our initial tests with an ECR-deposited layer on Al, de-adhesion of the layer occurred. We believe this can be overcome by biasing the specimen to obtain higher energy ions that penetrate through the layer/substrate interface and intermix them to provide increased adhesion.

The $\mathrm{Al}(\mathrm{O})$ layer materials are expected to have intrinsic hardnesses that are about three times their evaluated yield stresses, or 3-15 GPa. This range is below that of other coating materials, e.g., diamond-like carbon layers have hardnesses of $\sim 30 \mathrm{GPa}$ [31], and that of TiN is $\sim 21 \mathrm{GPa}$ [32]. Nonetheless, a hard coating based on a material 
with a metallic matrix may have additional benefits. In particular, because the $\mathrm{Al}(\mathrm{O})$ composite is $>70 \% \mathrm{fcc} \mathrm{Al}$ by volume and the small oxides are surrounded by the metal matrix, the layers are expected to have a ductility like that of Al. In applications where deformation of the layer and its substrate can occur, such as during repeated sliding contact or upon impact, the ductile layer may deform to remain in conformity with the substrate and not break away. Brittle fracture is not expected to occur in the $\mathrm{Al}(\mathrm{O})$ layers, but is more likely for ceramic-based coatings.

The $\mathrm{Al}(\mathrm{O})$ layers have another feature which favor them in some coatings applications: low resistivity. Our initial measurements show that the resistivity of $\mathrm{Al}_{0.75} \mathrm{O}_{0.25}$ layers produced by ECR deposition $(65 \mu \Omega-\mathrm{cm})$ is increased by a factor of $50 \mathrm{x}$ over pure $\mathrm{Al}$ deposited layers. Nonetheless, this resistivity is low enough for low current applications such as a sliding contact, and is comparable to silicides used for electical contacts in microelectronics devices [33]. If the $O$ concentration were lower and the material annealed, a conductivity high enough for conducting lines might be attained. Strengthening Al lines with oxides could reduced their failure rate due to void formation, according to recent modeling of the voiding phenomena [7].

The yield stresses of the pure $\mathrm{Al}$ layer, $0.2 \mathrm{GPa}$, is much lower than that of the $\mathrm{Al}(\mathrm{O})$ alloys, but nonetheless greatly exceeds the yield strength of well annealed, bulk Al, $0.041 \mathrm{GPa}$. This increase is due to its small grain sizes, ranging from 0.05 to $1.0 \mu \mathrm{m}$. The strengths of deposited Al layers have been observed by others to exhibit high strengths with decreasing grain size [20]. The influence of $\mathrm{O}$ on the $\mathrm{Al}$ grain size is also notable, reducing it by an order of magnitude down to 5-25 nm for the PLD alloys. The implantation of O into pure Al by Bader et al. was also found to reduce the grains from their original $0.6 \mu \mathrm{m}$ size to $0.35 \mu \mathrm{m}$ during post implantation thermal cycling up to $400^{\circ} \mathrm{C} \mathrm{[6].} \mathrm{They} \mathrm{inferred} \mathrm{that} \mathrm{recrystallization} \mathrm{and} \mathrm{the} \mathrm{growth} \mathrm{of} \mathrm{grains} \mathrm{during} \mathrm{the} \mathrm{cycling} \mathrm{with} \mathrm{accompanying}$ thermal stresses were blocked by the pinning of grain boundaries at oxide precipitates. Since fine oxides are present during our depositions, they probably inhibit grain growth and thus produce the refined grain structure observed for the plasma-deposited $\mathrm{Al}(\mathrm{O})$ materials.

\section{Conclusions}

Two new plasma synthesis methods, ECR plasma deposition and PLD, have been found to produce hard layers of $\mathrm{Al}$ strengthened with $\mathrm{O}$. The microstructure of these layers is similar to that of ion-implanted Al: nanometer-size $\gamma-\mathrm{Al}_{2} \mathrm{O}_{3}$ precipitates in a matrix of fcc $\mathrm{Al}$. Examination of these layers with nanoindentation and finite element modeling indicate that the layers have exceptionally high yield stresses of several gigapascals. These two depositions and ion implantation have in common the athermal injection of individual $\mathrm{O}$ atoms or molecules, which promotes the high density of fine oxides that is responsible for the high strengths. Based on work with O-implanted Al, improved tribological properties are expected for the plasma-deposited layers. Future applications may also take advantage of the high strength/hardness, electrical conductivity and metallic ductility of this composite material.

\section{Acknowledgements}

The authors wish to thank N. Baker of Nano Instruments, Inc., for capably performing the indentation work. The assistance of M. P. Moran with the TEM investigations, J. Bigbie with the PLD apparatus, and G. A. Petersen with ion implantation are gratefully acknowledged. The work of D. Marshall (U. Maine) in determining the roughness of the ECR layers and its temperature dependence contributed to our undertanding this process better. This work at Sandia National Laboratories was supported by the Division of Materials Sciences, Office of Basic Energy Sciences of the United States Department of Energy under contract DE-AC04-94AL85000.

\section{References}

1. R. J. Bourcier, S. M. Myers and D. H. Polonis, Nucl. Inst. Meth. B44, 278-288 (1990).

2. D. M. Follstaedt, S. M. Myers, R. J. Bourcier and M. T. Dugger, "Proc. Intl. Conf. on Beam Processing of Advanced Materials" (1992), eds. J. Singh and S. M. Copley (TMS, Warrendale, PA, 1993), pp. 507-517. 
3, M. T. Dugger, R. J. Bourcier, D. M. Follstaedt and S. M. Myers, Tribology International, in press.

4. J. C. Barbour, D. M. Follstaedt and S. M. Myers, Nuclear Instruments and Methods, in press.

5. J. A. Knapp, D. M. Follstaedt and S. M. Myers, submitted to Journal of Applied Physics.

6. S. Bader, P. A. Flinn, E. Arzt and W. D. Nix, J. Mater. Res. 9, 318-327 (1994).

7. E. Arzt and W. D. Nix, J. Mater. Res. 6, 731-736 (1991).

8. D. M. Follstaedt, S. M. Myers and R. J. Bourcier, Nucl. Inst. Meth. B59/60, 909-913 (1991).

9. R. J. Bourcier, D. M. Follstaedt, M. T. Dugger and S. M. Myers, Nucl. Inst. Meth. B59/60, 905-908 (1991).

10. Joint Committee on Powder Diffraction Standards, Card Index No. 10-425.

11. W. H. Gitzen, "Alumina as a Ceramic Material", (American Ceramic Society, Columbus, OH, 1970), pp. 3, 29. Note that cubic $\gamma-\mathrm{Al}_{2} \mathrm{O}_{3}$ is referred to as the $\eta$ phase in this reference.

12. S. M. Myers and D. M. Follstaedt, J. Appl. Phys. 63, 1942 (1988).

13. J. C. Barbour, J. S. Custer, D. M. Follstaedt, B. G. Potter and M. B. Sinclair, submitted to J. Vac. Sci. Technol.

14. D. K. Brice, Nucl. Inst. Meth. B44, 302 (1990).

15. D. Marshall, R. J. Lad, J. C. Barbour, D. M. Follstaedt and S. M. Myers, to be presented at the Fall Meeting of the Materials Research Society, Boston, Nov. 27-Dec. 1, 1995, Symposium I.

16. J. A. Knapp, Mat. Res. Soc. Symp. Proc. 236, 473 (1992).

17. G. K. Hubler, in "Pulsed Laser Deposition of Thin Films", eds. D. B. Chrisey and G. K. Hubler (John Wiley and Sons, New York, 1994) p. 353.

18. Nano Instruments, Inc., Knoxville, TN.

19. "Mechanical Behavior of Materials", eds. F. A. McClintock and A. S. Argon (Addison-Wesley, Reading, MA, 1966) p. 86, 453.

20. W. D. Nix, Metall. Trans. A20, 2217 (1989).

21. W. C. Oliver and G. M. Pharr, J. Mat. Res. 7, 1564 (1992).

22. ABAQUS/Explicit version 5.4, Hibbitt, Karlsson \& Sorensen, Inc., Pawtucket, RI.

23. J. A. Knapp, to be published.

24. "Atlas of Stress-Strain Curves", ed. H. E. Boyer (ASM International, Metals Park, OH, 1987) p. 383.

25. M. F. Doerner and W. D. Nix, J. Mater. Res. 1, 601 (1986).

26. "Binary Alloy Phase Diagrams", eds. T. B. Massalski, J. L. Murray, L. H. Bennett and H. Baker (ASM International, Metals Park, OH, 1986), Vol. 1, p. 143.

27. E. Orowan, "Symposium on Internal Stresses in Metals and Alloys" (Inst. of Metals, London, 1948) p.451.

28. J. D. Embury, Met. Trans. A 16A, 2192 (1985).

29. P. B. Hirsch and F. J. Humphreys, Proc. Royal Soc. London A318, 45 (1970).

30. C. R. Barrett, W. D. Nix and A.S. Tetelman, "The Principles of Engineering Materials" (Prentice-Hall, Englewood Cliffs, NJ, 1973) p. 227.

31. S. Falabella, D. B. Boercker and D. M. Sanders, Thin Solid Films 236, 82-86 (1993).

32. H. Holleck, J. Vac. Sci. Technol. A4, 2661-2669 (1986).

33. J. W. Mayer and S. S. Lau, "Electronic Materials Science: For Integrated Circuits in Si and GaAs" (Macmillan Publishing, New York, 1990), pp. 83, 284. 
J

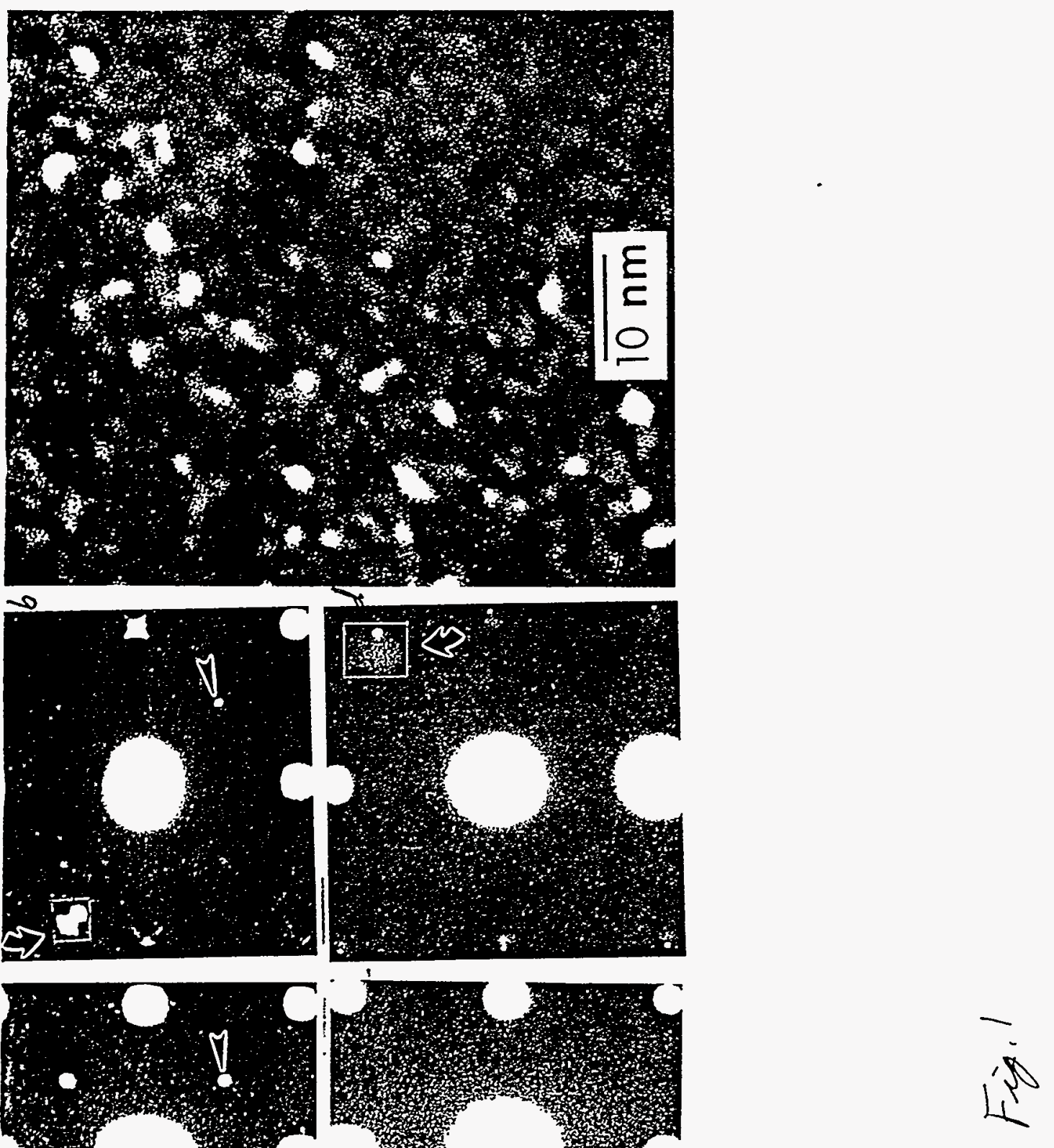



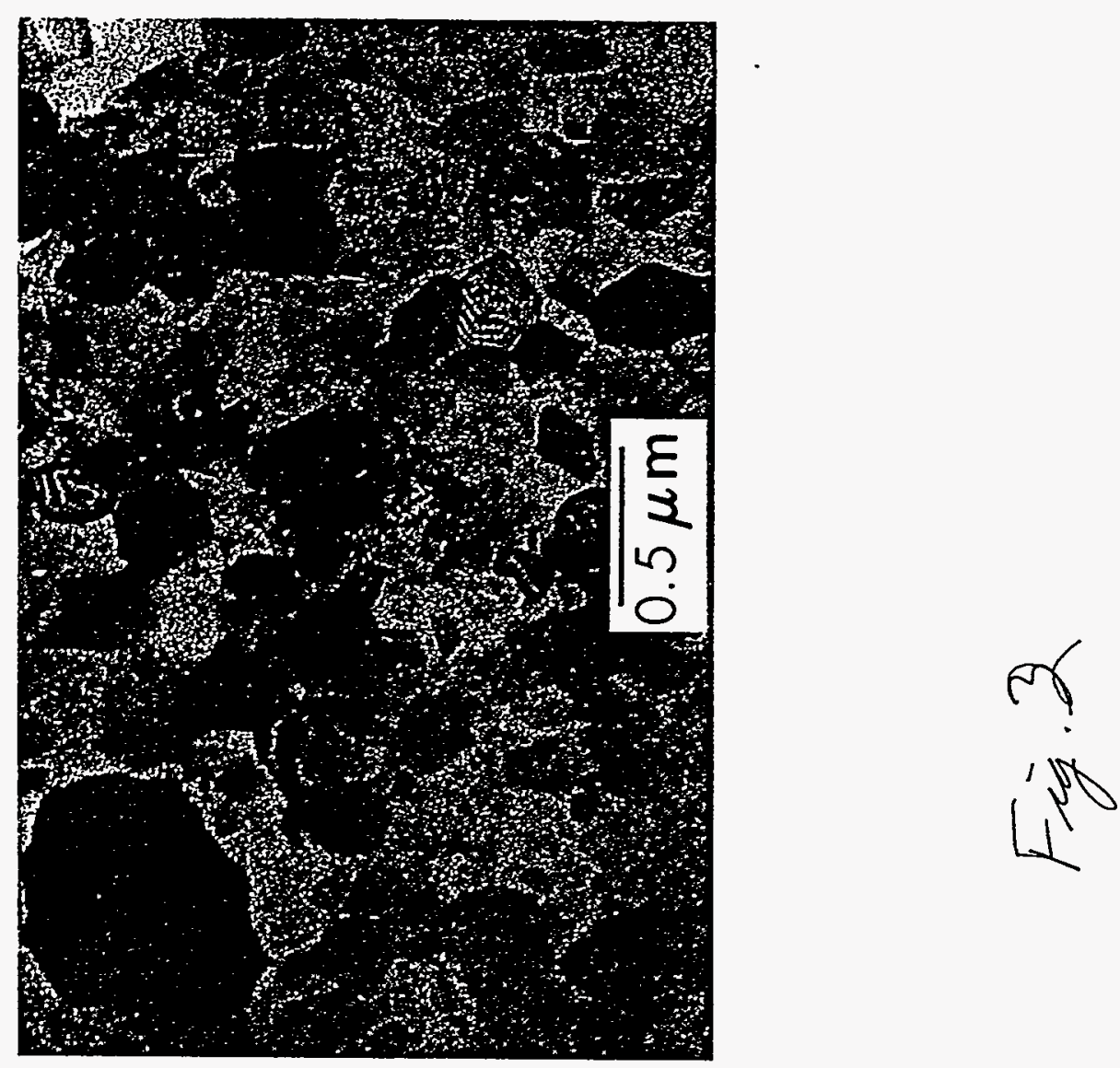

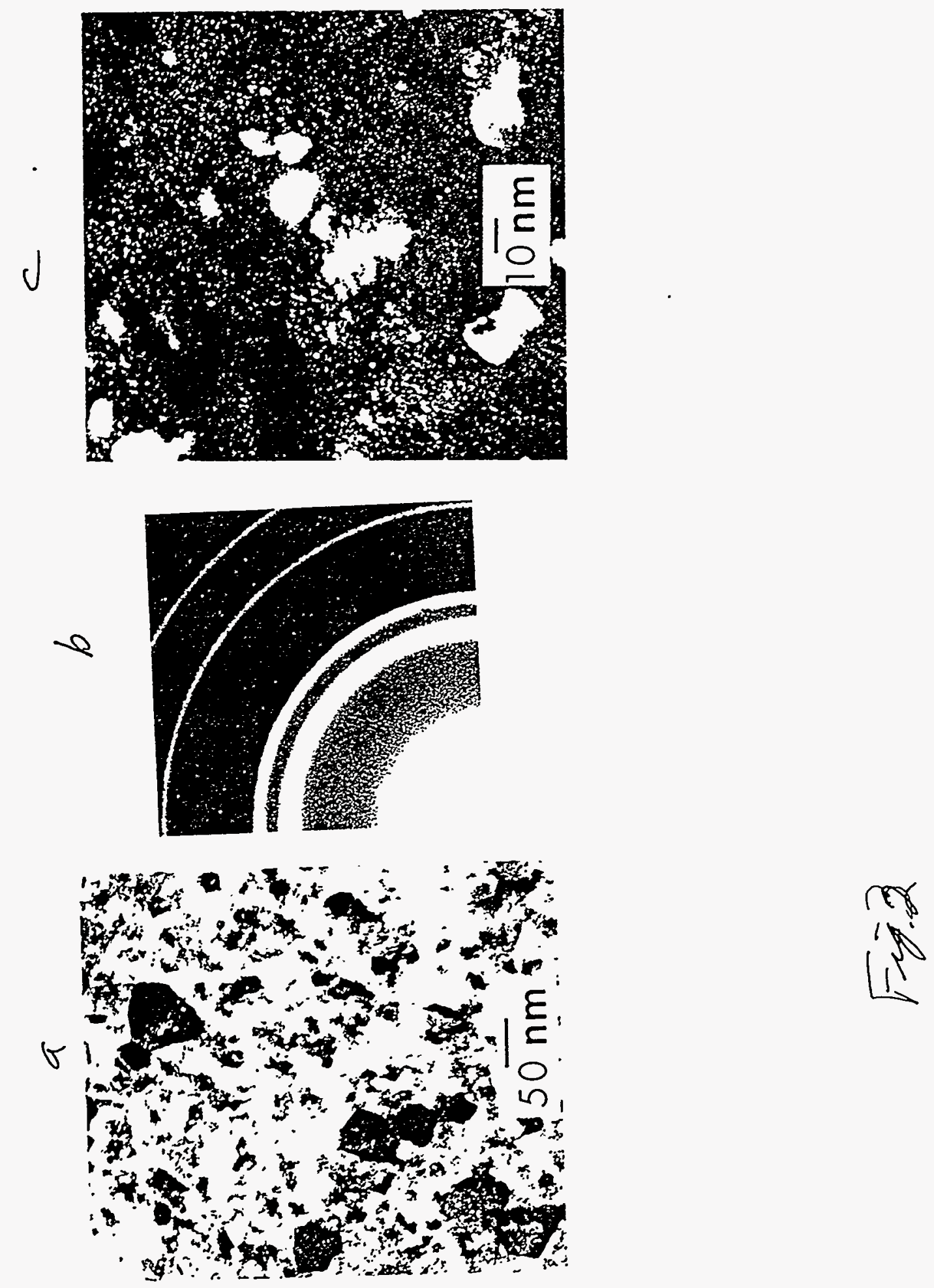

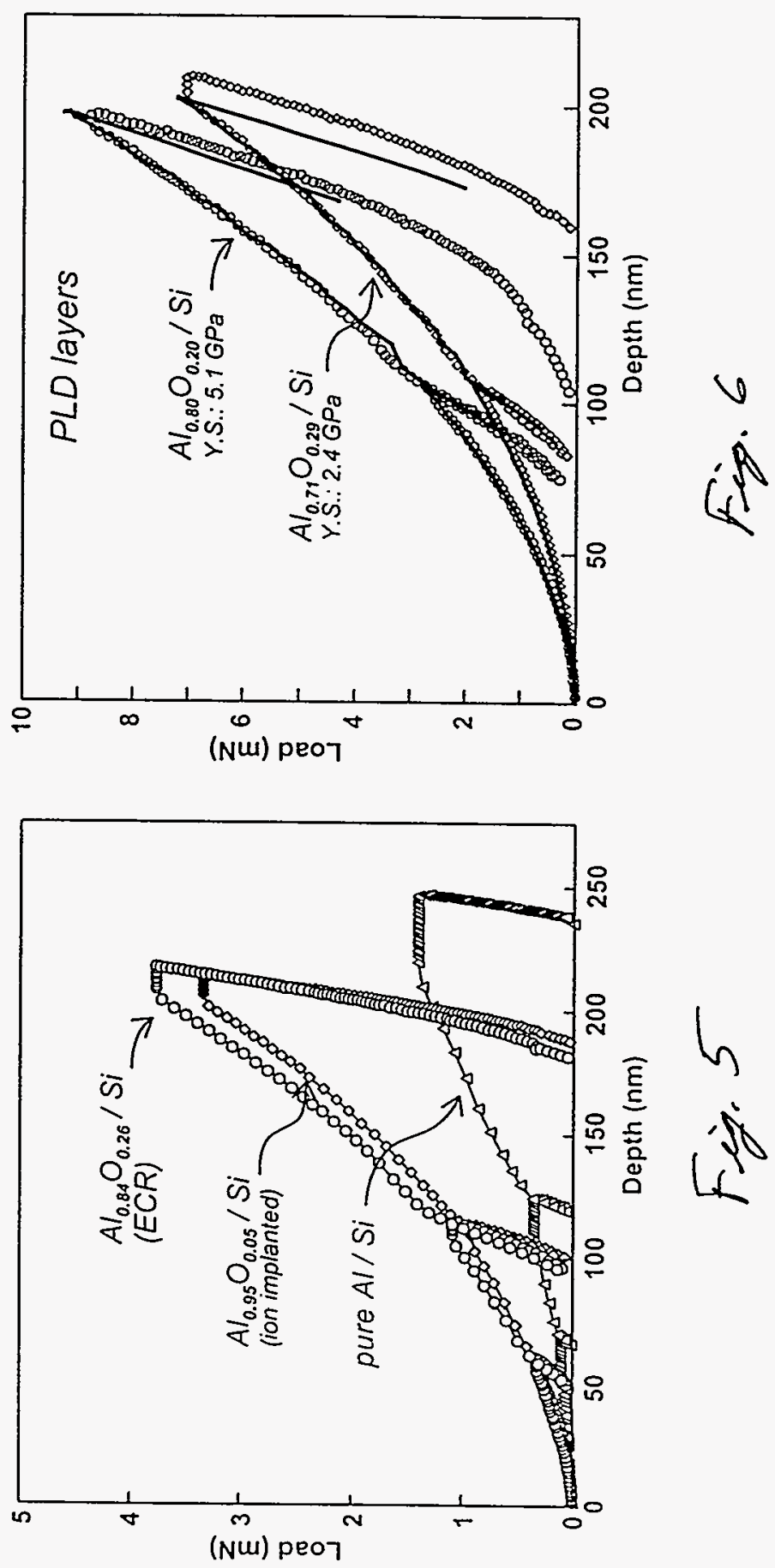

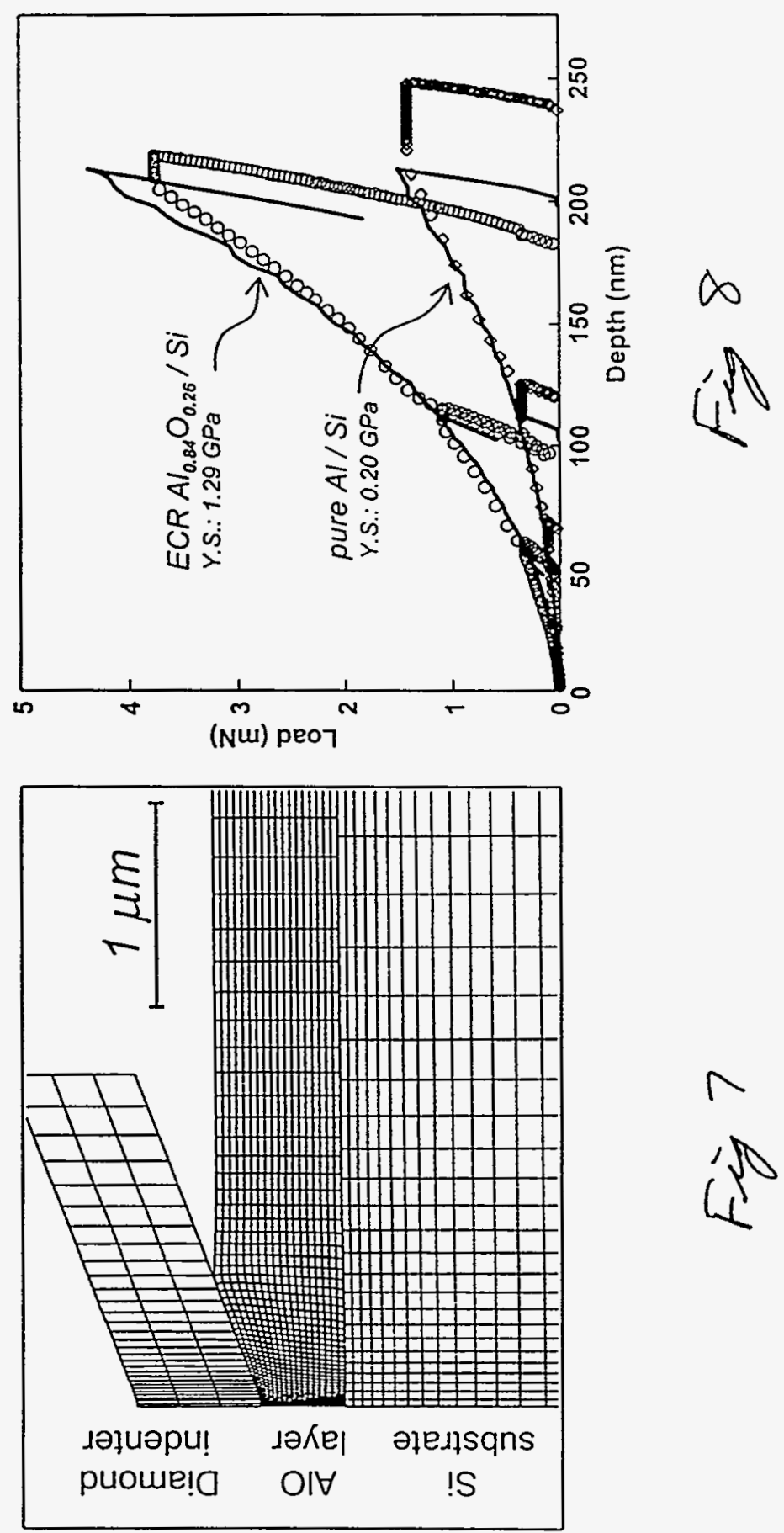


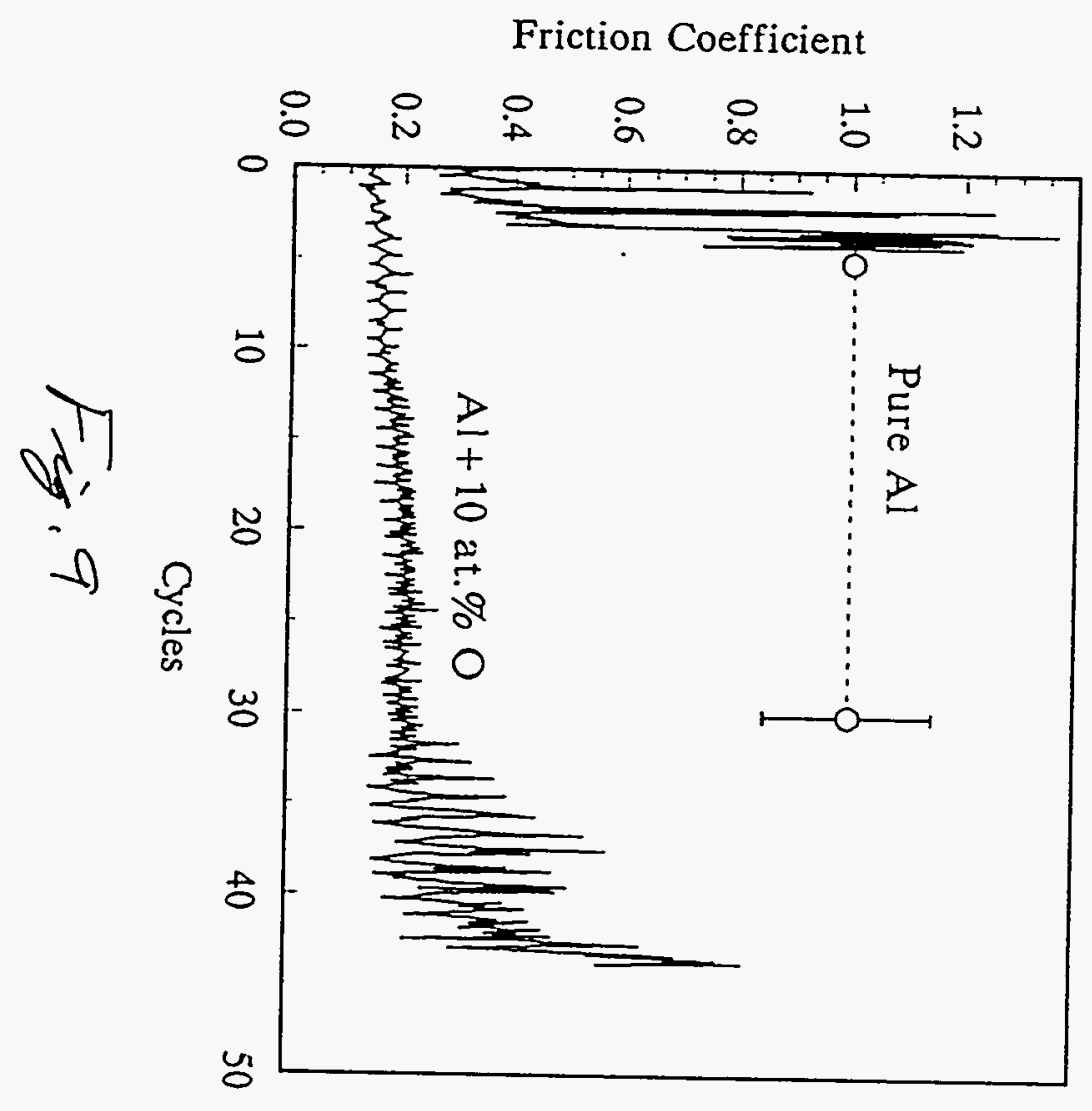

\section{DISCLAIMER}

This report was prepared as an account of work sponsored by an agency of the United States Government. Neither the United States Government nor any agency thereof, nor any of their employees, makes any warranty, express or implied, or assumes any legal liability or responsibility for the accuracy, completeness, or usefulness of any information, apparatus, product, or process disclosed, or represents that its use would not infringe privately owned rights. Reference herein to any specific commercial product, process, or service by trade name, trademark, manufacturer, or otherwise does not necessarily constitute or imply its endorsement, recommendation, or favoring by the United States Government or any agency thereof. The views and opinions of authors expressed herein do not necessarily state or reflect those of the United States Government or any agency thereof. 